\title{
TOWARDS A HIGH-RESOLUTION DRONE-BASED 3D MAPPING DATASET TO OPTIMISE FLOOD HAZARD MODELLING
}

\author{
D. Backes ${ }^{1,}$ *, G. Schumann ${ }^{2,3}$, F. N. Teferle ${ }^{1}$, J. Boehm ${ }^{4}$ \\ ${ }^{1}$ Research Unit Engineering Science, University of Luxembourg, 6 rue Richard Coudenhove-Kalergi, L-1359 Luxembourg - \\ (dietmar.backes, norman.teferle)@uni.lu \\ ${ }^{2}$ RSS-Hydro Sarl-S, Dudelange Innovation Hub, route de Volmerange, L-3593 Dudelange, Luxembourg - rss-hydro@outlook.com \\ ${ }^{3}$ School of Geographical Sciences, University of Bristol, Bristol, BS8 1SS, UK \\ ${ }^{4}$ Dept. of Civil, Environmental and Geomatic Engineering, University College London, Gower Street, London, WC1E 6BT UK - \\ j.boehm@ucl.ac.uk
}

Commission VI, WG VI/4

KEY WORDS: Urban flood modelling, DSM, Drone Photogrammetry

\begin{abstract}
:
The occurrence of urban flooding following strong rainfall events may increase as a result of climate change. Urban expansion, aging infrastructure and an increasing number of impervious surfaces are further exacerbating flooding. To increase resilience and support flood mitigation, bespoke accurate flood modelling and reliable prediction is required. However, flooding in urban areas is most challenging. State-of-the-art flood inundation modelling is still often based on relatively low-resolution $2.5 \mathrm{D}$ bare earth models with 2-5m GSD. Current systems suffer from a lack of precise input data and numerical instabilities and lack of other important data, such as drainage networks. Especially, the quality and resolution of the topographic input data represents a major source of uncertainty in urban flood modelling. A benchmark study is needed that defines the accuracy requirements for highly detailed urban flood modelling and to improve our understanding of important threshold processes and limitations of current methods and 3D mapping data alike.

This paper presents the first steps in establishing a new, innovative multiscale data set suitable to benchmark urban flood modelling. The final data set will consist of high-resolution 3D mapping data acquired from different airborne platforms, focusing on the use of drones (optical and LiDAR). The case study includes residential as well as rural areas in Dudelange/Luxembourg, which have been prone to localized flash flooding following strong rainfall events in recent years. The project also represents a cross disciplinary collaboration between the geospatial and flood modelling community. In this paper, we introduce the first steps to build up a new benchmark data set together with some initial flood modelling results. More detailed investigations will follow in the next phases of this project.
\end{abstract}

\section{INTRODUCTION}

\subsection{Background}

In the last 20 years, more than 2.3 billion people were affected by floods. It is in urban areas where assets and most people at risk from flooding are located. However, flooding in urban areas is most challenging to simulate correctly, and state-of-the-art flood inundation modelling is still often based on low resolution $2.5 \mathrm{D}$ bare earth models with $2-5 \mathrm{~m}$ ground surface distance (GSD). So far, current models do not consider fine detail or surface objects (microtopographic features) although they have a substantial influence on the flood simulations. It is expected that the integration of high-resolution 3D mapping from drone data could have a significant impact on the performance and accuracy of urban flood modelling and will help support flood mitigation and resilience strategies.

The market penetration of LiDAR in the mid-1990s has clearly revolutionized flood model development and accuracies of flood hazard predictions (Bates, 2012, 2004). Following the rapid developments of drone technologies during the last years, it seems effortless to produce dense 3D mapping data by using inexpensive consumer-grade drones and highly automated postprocessing software often based on Structure from Motion (SfM) algorithms. However, it is (still) unclear if such data provide suitable 3D mapping for the envisaged application and what the requirements for accurate and high-detail urban flood hazard modelling might be.

A benchmark study is therefore needed to define the accuracy requirements for urban flood modelling and to gain an understanding of thresholds and limitations of current methods, data and models.

In this context, Brazier et al., (2015), for instance, claim there is a shortfall in current remote sensing data provision in relation to the following two challenges that cannot be met with current satellite or airborne imaging survey technologies:

- Cost-effective capture of fine-scale spatial data describing the current hydrological condition and water resource status of catchments at user-defined time-steps;

- Data capture at fine temporal resolution for describing water system dynamics in soil moisture, vegetation, and topography in catchments where there are important downstream effects on water resources (e.g., floods, erosion events or vegetation removal).

In this study, we further stipulate that the aforementioned advantage, especially in relation to the second challenge

Corresponding author 
identified by (Brazier et al., 2015), would apply in particular to small streams and floodplain flow pathways that become hydraulically and geomorphologically very important during flash floods. However, given the small size and stream order of these streams but their high significance during flash floods nonetheless, they require detailed, high-resolution data on floodplain topology and channel geometry.

Hence, here we present an assessment of the value and applicability of a drone-acquired topographic data set in the context of floodplain and channel geometry mapping of a smallorder stream, first in a small agricultural sub-catchment to test data and model capabilities, before establishing benchmarks for data and flood models in a much more complex residential area that is prone to flash flooding.

\subsection{Local Area Flood Modelling}

In simple words, flood inundation models, also known as hydraulic models, simulate water flow volumes and depths within channel networks (commonly in 1-D) and in the adjacent floodplain lands when channel bank overtopping occurs and water spreads across low-lying topography (in 2-D). Such models are needed for predicting inundation as well as for flood event reanalysis and flood hazard estimation. Although traditionally applied to relatively small sections or reaches of rivers, recent advances in computational model code and computing power have enabled flood simulations over spatial and temporal scales much larger than in the past; in fact, such models can now be run at continental-to-global scales (Dottori et al., 2016; Sampson et al., 2015).

Given the recent popularity of flood hazard simulations to be performed across national or even global coverage with low resolution and poor quality data sets in topography, river geometry and stream flow or rainfall, there is, however, a growing need to establish very high-resolution benchmark test data sets and use cases of very high detail locally, with the objective to better understand the data-model interactions, limitations and computational requirements.

Allowing the flood model, i.e. the shallow-water equations, to capture preferential flow directions which occur in urban settings due to asymmetric building shapes and spacings and the alignment of buildings along streets.

At local coverage, over small areas $\left(<10 \mathrm{~km}^{2}\right)$, flood hazard modelling, or indeed shallow-water equations should preferably capture preferential flow directions which occur in rural agricultural and mainly in urban settings due to asymmetric building shapes and spacings and the alignment of buildings along streets (Sanders, 2008). Urban and agricultural areas are vulnerable to major flood damages due to the density of economic and social assets, and there is increasing interest in localized flood intensity predictions to implement flood risk reduction measures.

A number of models have been proposed for unsteady flood flows through urban landscapes, but the data needs and complexity are varied and it is not clear that the benefits of added complexity are justified by improved predictive skill (Schubert and Sanders, 2012). The best (flood) model, of course, depends on modelling objectives and constraints (Schubert and Sanders, 2012).

\subsection{Requirements}

Many challenges exist to establish requirements for developing a robust benchmark test data set and, in this study, we first attempt to establish those data and modelling capabilities for a small agricultural area before trying to define the requirements (data, model, computational) for a vulnerable residential area further upstream of the rural sub-catchment.

\subsubsection{Challenges in Flood Modelling}

In urban areas, a reference calculation or model using a detailed description of the street network and of the cross-sections of the streets, considering impervious residence blocks, but neglecting the flow interaction with the sewer network, can provide acceptable and accurate flood hazard modelling results. In addition, sensitivity analysis of various topographical and numerical parameters shows that results keep the same level of accuracy (Mignot et al., 2006). However, local flow modifications due to change of parameter values can drastically modify the local water depths, especially when the local flow regime is modified. Furthermore, the flow distribution to the downstream parts of the city can be altered depending on the set of parameters used (Mignot et al., 2006).

While variations of in-channel water levels (determined by local flow conditions) drive the timing and amount of water overtopping the river banks and spilling onto adjacent low-lying land, it is variations in floodplain topography that control floodplain flow paths and inundated area during a flood event. Thus, microtopography (refers to topographic variation about a mean surface trend with amplitudes much smaller than hillslope or basin scales (Thompson et al., 2010)) and floodplain features, such as buildings, walls, trees, etc., become important, particularly when interested in localized flow conditions and associated floodplain inundation at the small scale (Mason et al., 2003).

In the context of flood modelling, microtopographic features and variations in microtopography are only included in flood inundation (i.e. 2-D hydraulic) models when high-resolution, high-precision data on floodplain heights are available but in most cases their effects are parameterized in models of grid resolutions typically orders of magnitude larger than the microtopographic controls (Dottori et al., 2013).

\subsubsection{Challenges in Topographic Data Capture for flood modelling}

The field of topographic data capture from remote sensing platforms has seen great technological advances over the past decades. Increased capability of sensors and automated postprocessing workflows allow extracting high-resolution surface models from imagery captured from space borne and airborne platforms of various types (Chen et al., 2016; Dowman et al., 2012; Nex et al., 2015). Especially low altitude, small Unmanned Aerial Systems (UAS) or drones have quickly matured and are presenting a highly agile and effective tool for topographic mapping of small local areas (Haala et al., 2012; Remondino et al., 2012).

However, hydrologic modelling communities do not seem to take advantage of the improved 3D data capturing technologies yet, at least not as much as they could. Most complex hydrologic and hydraulic (flood inundation) modelling algorithms still rely mainly on 2.5D raster's DEMs at relatively low resolution, except for some isolated high-resolution (greater than $5 \mathrm{~m}$ ) case 
studies. Many data sources also lack adequate metadata about data currency capture technology, post processing and data quality.

Furthermore, the requirements of an 'ideal' or optimal DEM for flood modelling are not well understood yet. This might partly be the result of a lack of communication between both communities but also due to different priorities. While the Geospatial community thrives to capture and create data rich 3D models from large point clouds, the hydrological community requires a reduced but detailed $2.5 \mathrm{D}$ representation to apply current modelling algorithms and methodologies.

Following the increased capabilities to generate rich 3D point clouds from space borne, airborne imagery, and ever improving LiDAR sensors, a methodology is required to produce an optimised 2.5D Digital Terrain Model (DTM) for flood modelling from these rich point clouds. At the first step to produce a DTM, ground points have to be separated from surface points, which is known as filtering. Throughout the last decades, many filtering algorithms have been developed mainly for LiDAR based point clouds (Hui et al., 2018). They are categorized into slope-based, morphologically-based, interpolation-based and segmentation-based algorithms. The choice of the right filtering strategy applied to the data collected in this study to generate an optimal DTM for flood modelling is thus still rather unknown and should be investigated further.

\section{TEST SITE DUDELANGE}

Based on the requirements and consideration described in the previous section a new test site was identified which provides a realistic environment for urban flood simulation. The city council of Dudelange, proposed an area, which has been affected by flash flooding after heavy rainfall events in the past. The council holds records of past flooding events which provides and is investigating measures to improve flood vulnerability and resilience. Such data will provide valuable ground truth to benchmark the results of flood modelling.

\subsection{The test area}

The selected test site is situated in the Northern outskirts of the city of Dudelange and contains a catchment area of a local, small stream, which includes an urban, as well as, rural zone (Figure 1). A modern residential area with generous detached dwellings was developed along a hillside in the South-eastern part of the area. Buildings have been subject to flooding after heavy rainfall events due to the typical low permeability of the urban surfaces and the limited capacity of the underground drainage system . The rural area in the North-western part of the area consists mainly of farm land and a re-naturalised zone. Both zones together have an overall extend of approximately $1300 * 1300 \mathrm{~m}$.

While the rural, agricultural zone is well suited for capability testing of deployed flood modelling algorithms, the residential area will allow the investigation into urban flood modelling and model benchmarking using the high-resolution topographic data.

Once finished, this benchmarking dataset should be available to all interested researchers and support the hydrological, as well as, the geospatial communities alike. Over time, new geospatial and ground truth data sets will be added. The availability of evidence of actual flooding events and realistic flooding scenarios provides an ideal dataset to investigate the use of high-resolution DEMs captured from drone photogrammetry for urban flood modelling. The following sections will describe current datasets in detail.

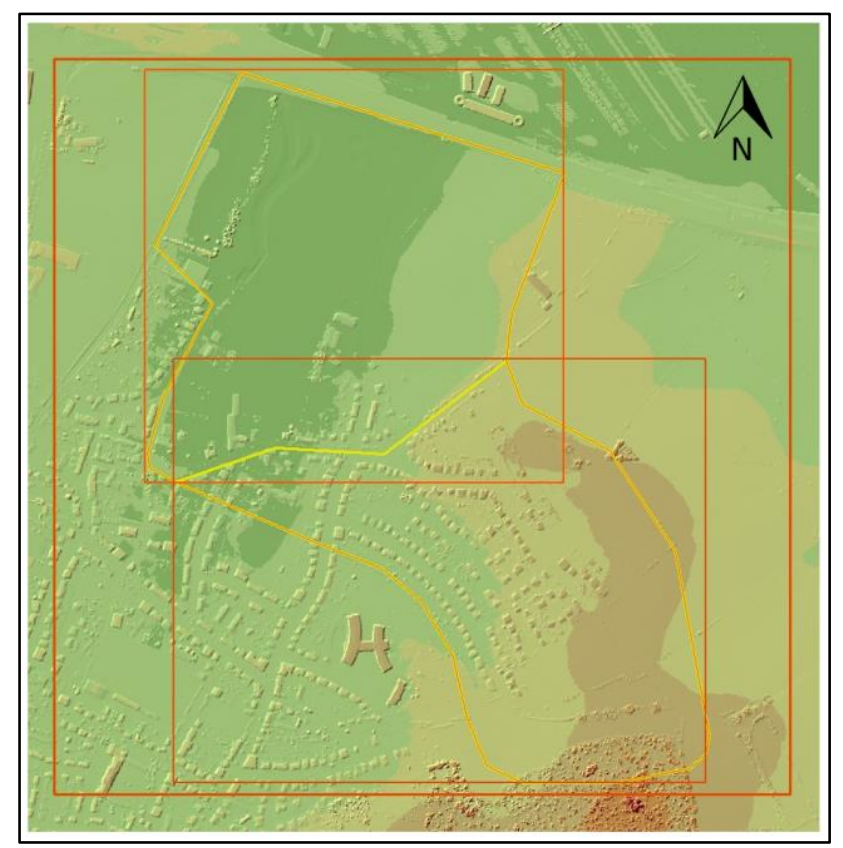

Figure 1. Overview map test site Dudelange

\subsection{Topographic Data sets}

The national Geoportal of the Grand Duchy of Luxembourg provides a wealth of national mapping layers, which are freely available via WMS services. Available data sets include topographic maps of various scales, boundary and land use information, as well as ortho photos collected over the past decade (ACT, 2019; Gouvernement.lu, 2019). 3D topographic datasets collected for this study include a LiDAR dataset with $1 \mathrm{~m}$ resolution from 2017, aerial photography with an average GSD of approximately $20 \mathrm{~cm}$ from 2018 and a drone-based survey from 2019 with an average GSD of $2 \mathrm{~cm}$.

\subsection{National 1m LiDAR coverage}

National LiDAR coverage with $1 \mathrm{~m}$ resolution is available via Luxembourg's open data portal (Gouvernement.lu, 2019). This dataset was commissioned by the national Air Navigation Administration (ANA) to provide electronic Terrain and Obstacle Data (eTOD) for civilian air traffic.

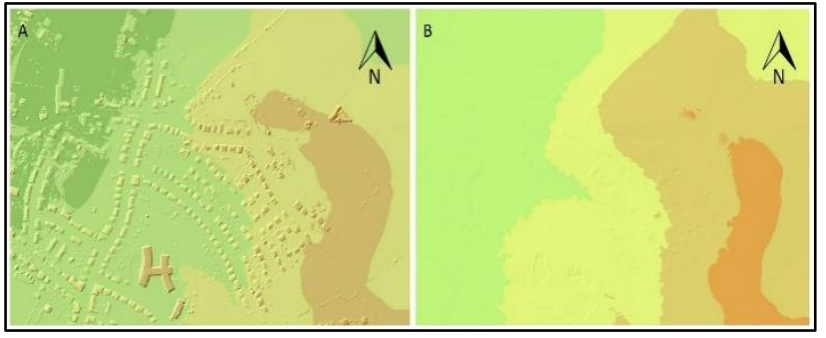

Figure 2. 1m Gridded LiDAR model as DSM (A) and DTM (B)

The LiDAR models available were the result of a LIDAR survey flight that was conducted in October 2017. The survey provided a $1 \mathrm{~m}$ gridded data set as Digital Surface Model (DSM) and Digital Terrain Model (DTM), which were released under open data agenda for public use. Both data sets where referenced to the national mapping system (LUREF). Further metadata e.g. about 
the state of post-processing and filtering or data quality were not available. This 2.5D LiDAR data set still represents the state-ofthe-art topographic data used for flood inundation modelling. In this study, this data set represents the base line data set for the flood modelling benchmark study.

\subsection{Aerial Photogrammetry}

An aerial image block was provided the 'Administration du cadastre et de la topographie' (ACT) of Luxembourg (Figure $3 \mathrm{~A})$. The aerial images where captured as part of the annual national photogrammetric survey in July 2018. The aerial survey was done using two Vexcel UltraCamXP cameras flown during two missions using an $80 \%$ front overlap and $60 \%$ site overlap at a GSD of approximately $20 \mathrm{~cm}$. The Erdas Imagine enhanced Terrain Extraction Module (eATE) was used to extract a dense point cloud (Figure 3B). This provides another topographic data layer for the proposed benchmark data set.

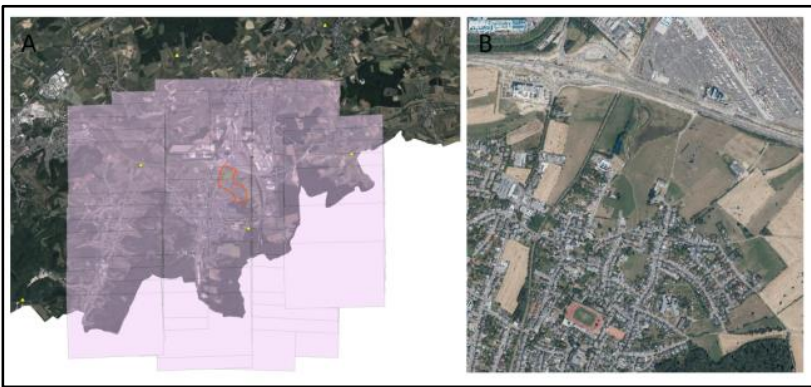

Figure 3. Aerial Photogrammetric block (A) and derived point cloud (B)

\subsection{Drone based Photogrammetric Dataset}

At the time this manuscript was put together, only the drone based survey had been conducted over the rural zone of the study site using an off-the-shelf Phantom4 Professional drone. The drone survey is described in detail in the following section.

\subsection{Ground Control}

A dense network of ground control points (GCP)s was established by using existing street markers and manmade objects. Especially manhole covers have been useful as GCPs in the rural areas. The GCPs where surveyed using network-RTK GNSS solutions with 3 min occupancy per point. The observed coordinates have a RMSE of less than $20 \mathrm{~mm}$. Overall 70 points where surveyed in the rural zone which provide $3 \mathrm{D}$ and as $2 \mathrm{D}$ GCPs (Figure4).

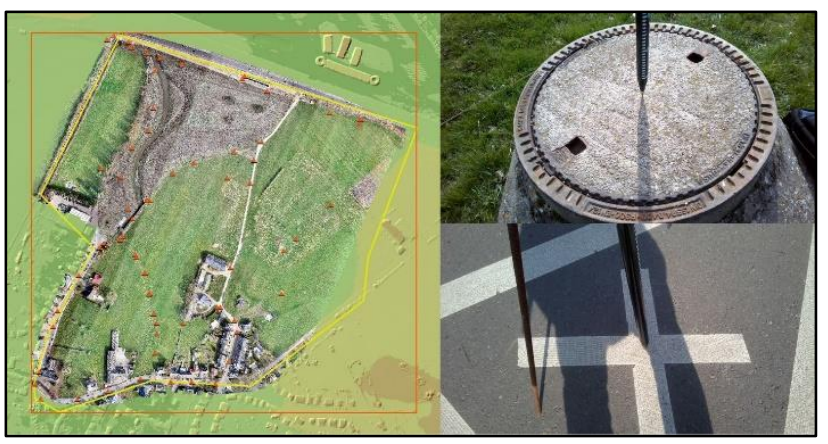

Figure 4. GNSS surveyed GCPs

\subsection{Expected data sets:}

Further topographic and ground truth data sets will be added as the project progresses. The final data set will include a full coverage of following data layers:

Aerial high-resolution LiDAR point cloud (16 points $/ \mathrm{m}^{2}$.

Aerial Photogrammetric block based on UltraCam imagery.

Low altitude drone based photogrammetric imagery.

Drone based LiDAR data.

Mobile mapping data.

Comprehensive terrestrial GCP network.

A permanently marked network of GCPs shall be suitable for aerial as well as mobile mapping surveys.

\section{DRONE PHOTOGRAMMETRY}

So far, only the rural zone of the study area, which is used for capacity testing, was covered with a drone survey. An off-theshelf Phantom4 Professional drone was used to collect a dense block of images over the zone. All data was processed using Pix4D Mapper (Version 4.3.33). The resulting dataset presents the highest resolution dataset for the intended flood modelling benchmark study.

Following a traditional mapping flight pattern, two different missions where conducted from an altitude of $60 \mathrm{~m}$ and $50 \mathrm{~m}$ respectively. The captured images have an average GSD bellow $2 \mathrm{~cm}$. Both image blocks cover the area with $80 \%$ front overlap and $70 \%$ site overlap. The flight lines between both blocks lie perpendicular to each other, so the combination of booth flight blocks result in a cross flight pattern. The combined block extends approximately $700 * 700 \mathrm{~m}$ and includes 2200 images (Figure 5)

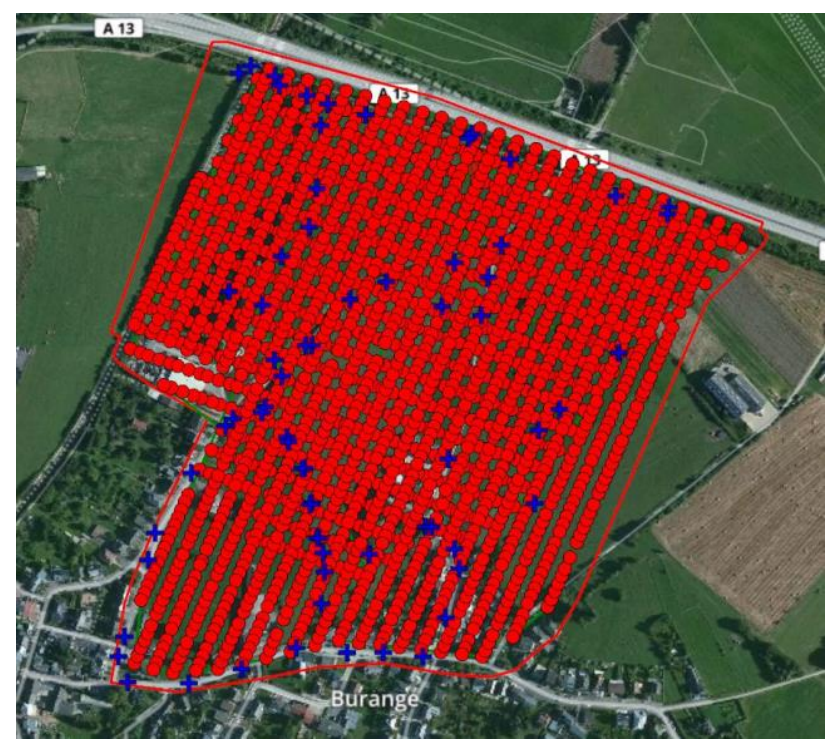

Figure 5. Combined flight plan of the combined drone surveys

Only GCPs which could be clearly identified were included in the aerial triangulations. Over 60 points were identified and manually measured in the combined image block. Since only natural or manmade features where surveyed the geometric distribution of GCPs is not ideal in the rural zone. Signalised points on the corners of the block and in the centre, which is mainly covered by farmland, would have increased the reliability 
and stability of the photogrammetric block. Table 1 shows the Root Mean Square Errors of the GCPs after the aerial triangulation. The results suggest an accuracy of $2 \mathrm{~cm}$ in height, which needs to be investigated further.

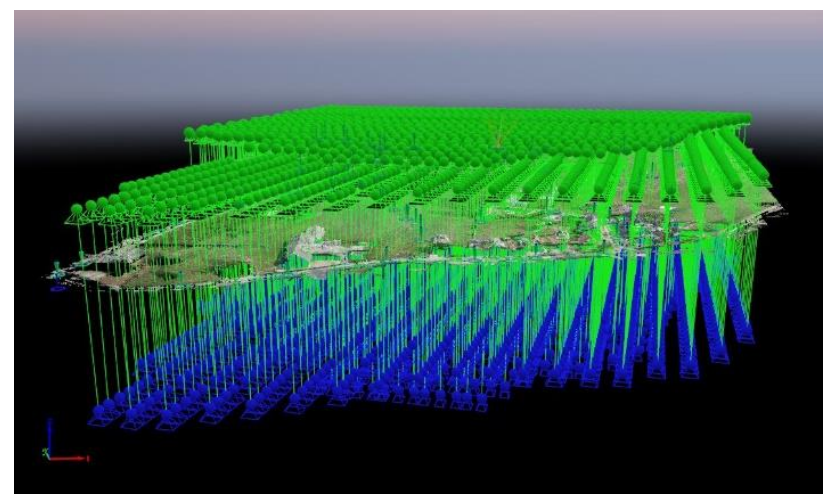

Figure 6. Results of the aerial triangulation - cross flight pattern

\begin{tabular}{|l|c|c|c|c|c|}
\hline \multicolumn{2}{|l|}{ Triangulations } & \multicolumn{3}{c|}{$\begin{array}{c}\text { RMSE } \\
{[\mathrm{m}]}\end{array}$} \\
\hline & Img. & GCPs & $\mathrm{X}$ & $\mathrm{Y}$ & $\mathrm{Z}$ \\
Block 1 & 771 & 41 & 0.018 & 0.015 & 0.055 \\
Block 2 & 1439 & 62 & 0.014 & 0.013 & 0.019 \\
Combined & 2210 & 62 & 0.016 & 0.014 & 0.020 \\
\hline
\end{tabular}

Table 1 Accuracy Geolocation of GCPs after triangulation

Figure7 shows the perspective view of final dense point cloud. This point cloud is the source for the derivation of DTM for surface modelling.

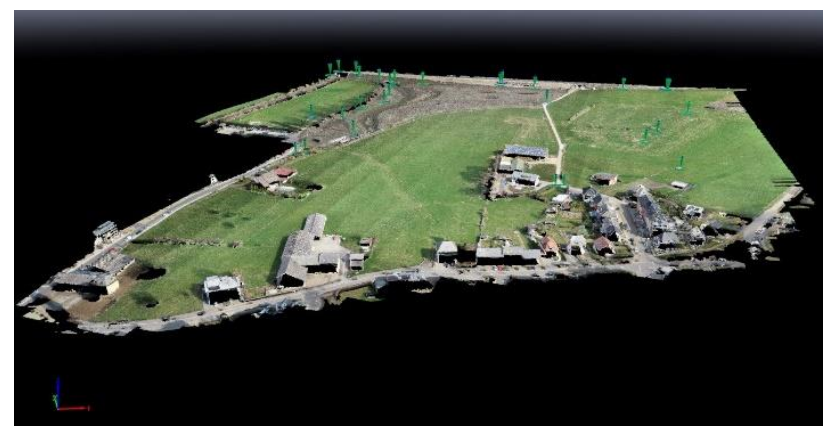

Figure 7. Perspective view dense point cloud

\section{FLOOD MODELLING}

As mentioned before, in this paper, we describe the setup and initial result of a capabilities study carried out in the rural zone. Since most of this region and small catchments are prone to flash flooding from intense but short-lived rainstorms, rather than typical large-area riverine flooding, we simulate a short duration rainstorm over the floodplains from the topography derived from LiDAR and drone photogrammetry.

The flood model used in this particular study is the widely used research code of the inertial version of the LISFLOOD-FP hydraulic model (Bates et al., 2010). This model is a regular raster grid model (Figure 8) and predicts water depths in each grid cell at each time step using a simplified version of the shallow water equations (momentum and continuity of water flow) and only neglects local convective acceleration, assumed negligible. The model can simulate the dynamic propagation of flood waves over fluvial, coastal and estuarine floodplains. The particular version used in this study also allows for direct rainfall as model input data, which is routed across the landscape following a simple flow accumulation and directional hydrologic routing algorithm (Sampson et al., 2013). In order to avoid excessive computational expenses, a rainfall water depth threshold is typically set at $1 \mathrm{~cm}$, after which the shallow water equations of the hydrodynamic model continue routing the water and estimate flow depths.
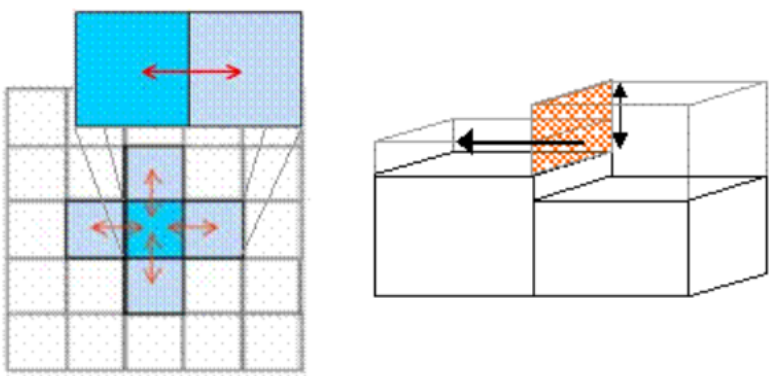

Figure 8. Abstract representation of the LISFLOOD-FP regular grid model (modified from University of Bristol).

\section{FLOOD SIMUALTION RESULTS}

The aim of the modelling of water depths across the rural area from a short rainstorm was to test basic capabilities of the flood model and to investigate whether a grid spacing in topography, much greater than that typically available from LiDAR derived surface rasters (coarser than $1 \mathrm{~m}$ ) will improve the simulations.

To this end, a simple comparison approach was employed, using the rasterised DTM at $1 \mathrm{~m}$ resolution from LiDAR. For data set commensurability, the drone DTM was aggregated to the same pixel spacing using a simple nearest neighbour averaging, before raining on both DTMs and simulating water flow and depths with the LISFLOOD-FP model.

The simulated rainstorm was based on an actual storm over 1.5 days obtained from inverting microwave signals during a longer rainfall event. This rainfall data set (Figure 9) was sufficiently adequate for the purpose of this study.

The water depth simulation results for the LiDAR- and dronebased DTMs are shown in Figure 2 and the differences in both DTMs and the associated water depths simulations are illustrated in Figure 10.

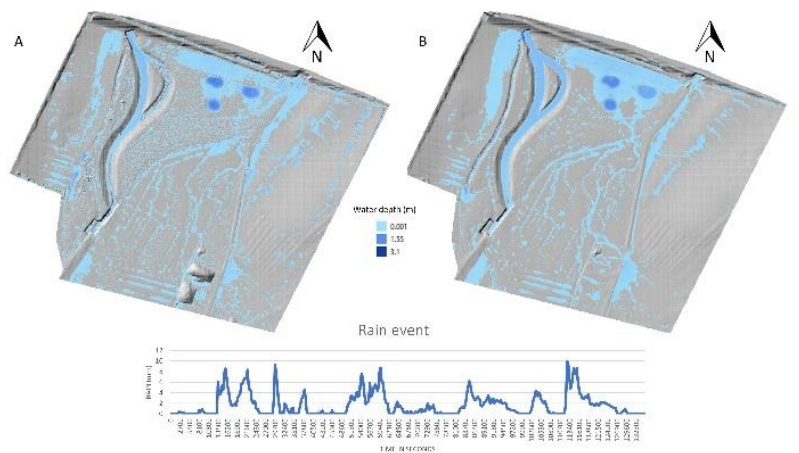

Figure 9. Water depth from direct rain on drone DTM (A) and LiDAR DTM (B). Simulated with a full 2-D LISFLOOD-FP hydraulic model code. 

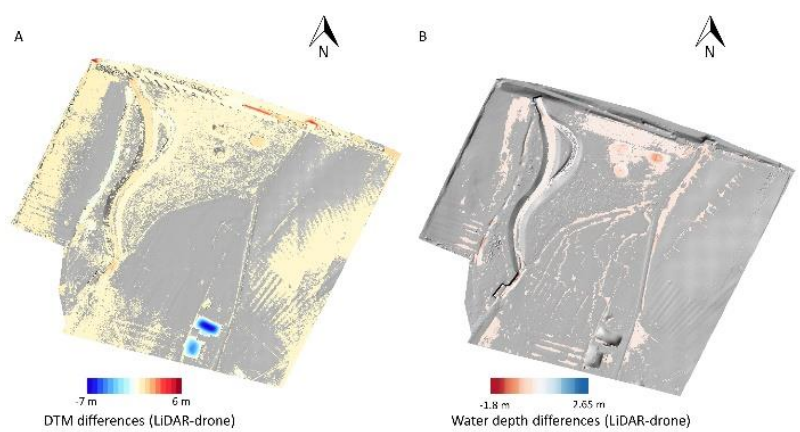

Figure 10. Differences in (A) DTM heights and (B) simulated water depths based on LiDAR and drone, respectively.

As expected, the water depth simulation results in Figure 9 highlight that the modelling of water flow and depths is greatly dependent on and affected by even small differences in terrain heights, which may be inherent to the technology or may stem from differences in the filtering process applied to remove large surface features, such as buildings and tall vegetation. However, much more strikingly, Figure 10 clearly illustrates that differences in heights between the two DTM technologies employed are not necessarily reflected in water depth differences. In fact, in the capability case presented, there is indeed no apparent correlation between direct topographic height differences and water depth differences. This may seem counterintuitive as topography is the main driver of water flow, however, it is clear that subtle differences in microtopographic features that control ultimately the flow paths across the landscape have much greater impact on the flow, pooling and final depths of water. This is clearly what can be seen in the results here and which needs to be investigated in greater detail.

Although the importance of microtopographic features on flow propagation across terrains is known for a long time, the quantification of this is only possible with much higher resolution data sets, like those generated from drones (or terrestrial mobile LiDAR). The extent of this significance, however, needs to be analysed more in detail and across much more complex terrain. Following on from this initial study, we will benchmark DSMs derived from LiDAR and photogrammetry with different resolutions in the residential area.

\section{CONCLUSIONS}

This paper has shown work in progress. First data sets have been acquired which enabled some initial but important investigations. One of the main preliminary finding is the importance of microtopography on flood flow control, which, of course, is well known and has been investigated by some studies (Dottori et al., 2013; Mason et al., 2003; Thompson et al., 2010); however, its quantification is less obvious and not straightforward. The study and drone data sets presented here has allowed a first step analysis in this direction.

The final data set will consist of comprehensive topographic mapping layers a well as additional evidence of past flood events. Once assembled the dataset will be made freely available to any interested scientist.
The project also represents a promising interdisciplinary collaboration between flood modelling and geospatial communities.

\section{ACKNOWLEDGEMENTS}

The authors greatly appreciate the administrative and logistical support of the City Council of Dudelange in this project. Also acknowledged are the Luxembourg Administration du cadastre et de la topographie (ACT) and the public data portal Luxembourg (data.public.lu) for the provision of the airborne data sets.

\section{REFERENCES}

ACT, Administration du cadastre et de la topographie, 2018. The national Geoportal of the Grand Duch of Luxembourg [WWW Document]. Geoportal. URL http://www.geoportail.lu/en/ (accessed 4.2.19).

Bates, P.D., 2012. Integrating remote sensing data with flood inundation models: how far have we got? Hydrol. Process. https://doi.org/10.1002/hyp.9374.

Bates, P.D., 2004. Remote sensing and flood inundation modelling. Hydrol. Process. https://doi.org/10.1002/hyp.5649.

Bates, P.D., Horritt, M.S., Fewtrell, T.J., 2010. A simple inertial formulation of the shallow water equations for efficient two dimensional flood inundation modelling. J. Hydrol. 387, 33-45.

Brazier, R.E., Jones, L., DeBell, L., King, N., Anderson, K., 2015. Water resource management at catchment scales using lightweight UAVs: current capabilities and future perspectives. J. Unmanned Veh. Syst. https://doi.org/10.1139/juvs-2015-0026.

Chen, J., Dowman, I., Li, S., Li, Z., Madden, M., Mills, J., Paparoditis, N., Rottensteiner, F., Sester, M., Toth, C., Trinder, J., Heipke, C., 2016. Information from imagery: ISPRS scientific vision and research agenda. ISPRS Journal of Photogrammetry and Remote Sensing, "State-of-the-art in photogrammetry, remote sensing and spatial information science" 115, 3-21. https://doi.org/10.1016/j.isprsjprs.2015.09.008

Dottori, F., Di Baldassarre, G., Todini, E., 2013. Detailed data is welcome, but with a pinch of salt: Accuracy, precision, and uncertainty in flood inundation modeling. Water Resour. Res. https://doi.org/10.1002/wrcr.20406.

Dottori, F., Salamon, P., Bianchi, A., Alfieri, L., Hirpa, F.A., Feyen, L., 2016. Development and evaluation of a framework for global flood hazard mapping. Adv. Water Resour. 94, 87-102. https://doi.org/http://dx.doi.org/10.1016/j.advwatres.2016.05.00 2.

Dowman, I.J., Jacobsen, K., Konecny, G., Sandau, R., 2012. High resolution optical satellite imagery. Whittles Publishing, Caithness, Scotland.

Gerke, M., Przybilla, H.-J., 2016. Accuracy Analysis of Photogrammetric UAV Image Blocks: Influence of Onboard RTK-GNSS and Cross Flight Patterns. Photogrammetrie Fernerkundung - Geoinformation 2016, 17-30. https://doi.org/10.1127/pfg/2016/0284.

Gouvernement.lu, 2019. Portail Open Data Luxembourg [WWW 
Document]. URL https://data.public.lu/en/ (accessed 4.2.19).

Haala, N., Cramer, M., Weimer, F., Trittler, M., 2012. Performance Test on UAV-Based Photogrammetric Data Collection. Int. Arch. Photogramm. Remote Sens. Spatial Inf. Sci., XXXVIII-1/C22, 7-12.

Hui, Z., Cheng, P., Ziggah, Y.Y., Nie, Y., 2018. A threshold-free filtering algorithm for Airborne LiDAR point clouds based on expectation-maximization. ISPRS Ann. Photogramm. Remote Sens. Spatial Inf. Sci. XLII-3, 607-610. https://doi.org/10.5194/isprs-archives-XLII-3-607-2018.

Mason, D.C., Cobby, D.M., Horritt, M.S., Bates, P.D., 2003. Floodplain friction parameterization in two-dimensional river flood models using vegetation heights derived from airborne scanning laser altimetry. Hydrol. Process. 17, 1711-1732.

Mignot, E., Paquier, A., Haider, S., 2006. Modeling floods in a dense urban area using 2D shallow water equations. J. Hydrol. 327, 186-199.

Nex, F., Gerke, M., Remondino, F., Przybilla, H.-J., Bäumker, M., Zurhorst, A., 2015. ISPRS Benchmark for Multi-platform Photogrammetry. ISPRS Ann. Photogramm. Remote Sens. Spatial Inf. Sci., II-3/W4) p. 135-142. doi.org/10.5194/isprsannals-II-3-W4-135-2015.

Remondino, F., Barazzetti, L., Nex, F., Scaioni, M., Sarazzi, D., 2012. UAV Photogrammetry for mapping and 3D modelling current status and future perspectives. Int. Arch. Photogramm. Remote Sens. Spatial Inf. Sci., XXXVIII-1/C22 pp. 25-31. https://doi.org/10.5194/isprsarchives-XXXVIII-1-C22-25-2011.

Sampson, C.C., Bates, P.D., Neal, J.C., Horritt, M.S., 2013. An automated routing methodology to enable direct rainfall in high resolution shallow water models. Hydrol. Process. https://doi.org/10.1002/hyp.9515.

Sampson, C.C., Smith, A.M., Bates, P.B., Neal, J.C., Alfieri, L., Freer, J.E., 2015. A high-resolution global flood hazard model. Water Resour. Res. 51, 7358-7381. https://doi.org/10.1002/2015WR016954.

Sanders, B.F., 2008. Integration of a shallow water model with a local time step. J. Hydraul. Res. 48, 466-475. 